\title{
The Laughing EFL Classroom: Potential Benefits and Barriers
}

\author{
Robert Stroud $^{1}$ \\ ${ }^{1}$ Kanagawa University High School, Japan \\ Correspondence: Robert Stroud, Kansei Gakuin University, Hyogo, Japan. E-mail: chelseaboybob@hotmail.com
}

Received: June 29, 2013 Accepted: July 23, 2013 Online Published: September 4, 2013

doi:10.5539/elt.v6n10p72 URL: http://dx.doi.org/10.5539/elt.v6n10p72

\begin{abstract}
The use of humor in EFL across the world has been widely discussed as an effective way to create a more comfortable, productive classroom environment in language learning. However, student-perceived benefits of both teacher and student-produced humor in the more specific context of a Japaneselanguage classroom have not been explored in any great detail. Two surveys of 104 Japanese high school students and a set of interviews revealedas expected positive feedback on general classroom humor usage, with noticeable positive effects perceived as improvements in retention, willingness to participation, enjoyment in learning and classroom atmosphere, as well as a lowering of anxiety.However, regardless of thisclear preference for humor inclusion in learning, several potential barriers were identified to help offer reasons why some students may not wish to use humor in class themselves. These included teacher disapproval, student confidence issues and language problems with being humorous in the L2. This study concludes with a suggested ten-step guideline for teachersto follow to harness humor as a potential catalyst for learningfor differing classes, based on this report's findings.
\end{abstract}

Keywords: humor, EFL, motivation, anxiety, retention, participation

\section{Introduction}

The idea of using humorous materials, gesticulations, anecdotes or jokes for example can seem appealing to teachers as a way to create a relaxed classroom environment with motivated learners. In fact, it has been shown that the incorporation of humor into the design of EFL classes and courses should, as one would expect, have just such positive effects on learning (Askildson 2005; Chee 2006; Golchi and Jamali 2011; Gorham and Christophel 1990; Schmitz 2002).

Differences between Japanese and non-Japanese styles of humor usage can sometimes be vast (Oda 2006: 15-26). Similarly, opinions and comprehension of humor in educational institutes in far-eastern countries such as Japan may vary greatly from that of in western nations for example (Bell 2007; Tamaoka and Takahashi 1994; Zhao and Fan 2010). This study considers the perception of Japanese learners (high school students in this case) of humor usage during class time.

Japanese learners may tend to be more familiar with the traditional teacher-centred classroom environment in learning, where the teacher will take up much of the speaking time and set the mood as to how students should be behaving or what they should be producing exactly in class. Japanese high school students sometimes lack any real experience of student-centred classes in language learning (where the teacher acts more as a facilitator and encourages more autonomy in the students).

When considering humor in the Japanese high school context, teacher-created and student-created humor should be separated as two differing sources. Students may feel that a humorous teacher(who makes them laugh with certain actions, dialogue, or materials they provide or show the class) is enhancing their learning with benefits such as helping students learnand retain difficult material (Aboudan 2009; Bell 2005; Ghaffari 2012). However, the same students may not feel that similar humorous contributions made by themselves to a class have the same effects on their learning. In fact, asking Japanese learners to be humorous in the L2 might not be as beneficial as first assumed if they feel a lack of confidence to do so for example. By looking at teacher and student humor usage separately in this study differences in the perceived benefits of both are explored. In doing so, teachers can become more aware of considerations needed for language classes and syllabus design when considering humor with Japanese learners.

As already stated, although the incorporation of humor into teaching practices, materials and syllabus design arguably has the potential to yield obvious benefits for learners (such as improved enjoyment in learning), it is 
not uncommon to see students hesitant to be humorous in class. When students feel the use of humor by themselves (through actions, verbal or written communication in class) is not significantly beneficial or motivational for them, barriers are clearly present to this use of humor. Obvious examples may be student shyness or teacher disapprovalof apparently 'wild' classes laughing loudly too often, but more data is needed to identify what the main barriers may in fact be. Upon exploring the barriers that humor may be facing for implementation at present in Japanese high school classes, steps can be taken to move forward towards using humor in EFL as a potential catalyst for learning.

\section{Literature Review}

\subsection{Defining 'Humor'}

Defining the meaning of 'humor' with Japanese high school students has been found to be not as straight-forward as one would hope (Quock 2007). The closest known adjective in the Japanese language to express something humorous is omoshiroi. However, whenlooking up in various dictionaries what the word translates as in English meanings such as interesting, amusing, entertaining, exciting, thrilling and witty can be found. From the standpoint of a native English speaking teacher in Japan, these words clearly do not perfectly correspond with the intended meaning of the word and a clearer explanation is needed for students to fully grasp what 'humor' is referring to.

Additionally, there has been extensive research into differing types of humor usage in class. One example is universal versus cultural humor (Schmitz 2002), referring to humor specific to one culture in the world (cultural), or humor which can be understood without being lost in translation due to language or cultural issues (universal). In the context of Japanese students this could refer to humor about family relationships specific to Japan for example (cultural humor which students can relate to and find humorous) orwatching a Charlie Chaplin movie, in which gesticulations and body language can be viewed as humorous by a large number of cultures (universal humor). Other examples of humor types are actual versus non-actual (things that are real or not in the world and seen as humorous for that reason), normal versus abnormal (when something is strange for example and viewed as humorous), or possible versus impossible (when an impossible scenario is viewed as humorous perhaps) (Raskin and Attardo 1994).

With so many different examples of humor existing within language, what it is exactly about something which makes students laugh can vary greatly and can sometimes be unexpected for teachers. Considering this, along with the difficulty of defining what humor refers to for students in Japan, a simplified approach was adopted in this paper. Humor was defined and explained to participants as 'something visual or audible which results in laughter (rather than just increased interest for example) because it is amusing'. Prior to the experimental surveys and interviews this was made clear to students and serves as the definition of humor throughout this study. Even though this was a very simplified view to take of what humor is and results in, it was adequate enough to ensure that humor-usage within learning was understood and could be examined with significant validity and reliance.

\subsection{Teacher versus Student Humor}

Humor can occur through several different areas of interaction in a classroom. It is not only what is said by a teacher which may be humorous to a class, but also the visuals they show, the non-verbal gestures they make, or even games that they play in front of a class which might draw a humorous response. By breaking humor down into forms such as verbal, visual, auditory and textual (Chee 2006; Shade 1996: 2) we might find that different sources of humorare reported to result in different effects on classroom learning.

Another point that requires attention is the difference between what students observe from the teacher and what they are asked to do themselves. There seems to be little research into student preferences between the two in learning. Finding out whether there are differences in the perceived positive effects on learning of student versus teacher-created humor would be useful indeed and these two areas should alwaysbe considered separately in research.

With consideration for the potential classroom sources of humor mentioned above, the four main sources explored in this study were:

1) The teacher's actions and dialogue - things which the teacher says, discusses, jokes about, or gesticulates.

2) The teacher's materials and visuals - hand-outs, pictures, videos, realia, or other such material the teacher shows the class.

3) The students' actions and dialogue - things the students are asked to say, do, discuss or present to others.

4) The students' materials and visuals - worksheets, pictures, video clips, or other such materials students are 
told to produce.

The perceived effects on learning of using humor through these separate sources by students are examined later in this study.Particular interest lay more with the effects of student-created humor on learning, as teacher-created humor was expected to be reported almost certainly as having an all-round positive effect on learningby students (as already discussed).

\subsection{Proposed Benefits of Humor-Usage}

Past research has looked at opinions related to using humorin the classroom (Minchew and Hopper 2008; Torok, McMorris and Lin 2004) and what positive effects such humor may have on learning in general (Gorham and Christophel 1990), on student anxiety (Golchi and Jamali 2011)and on class atmosphere (Aboudan 2009) for example. It has recently been recommended as not only a good way to aid communicative language learning, but also for different areas of language learning such as singing songs (Rafiee, Kassaian and Dastjerdi 2010) orteaching reading (Hayati, Shooshtari and Shakeri 2011). A brief summary of what the main benefits of humorfor communicative language classroom students are thought to be are:

- Lowered student anxiety

- Improved retention

- Improved student participation

- Increased enjoyment in learning for students

- Amore comfortable classroom atmosphere.

Upon viewing the above benefits of humor to learning, teachers could be forgiven for believing that humor should be heavily incorporated into classes to improve learning. However, humorcan act as what Askildson (2005: 48) called a 'double-edged sword'. The encouragement of humorous class content should always take into account the potential for overuse of humor resulting in an undisciplined, overly playful environment rather than a focused, motivated and productive one. Whilst positive effects are very likely, such fears exist for both students and teachers when considering the use of humor and such potential barriers to the effective use of humor in class will now be discussed.

\subsection{Barriers to Using Humor}

Perhaps the most obvious barrier for a student (anywhere in the world) to speak out in the L2 in front of others, particularly if they expected to be humorous, is confidence to do so. Previous studies have generally viewed humor ashaving a positive effect on student confidence (Aboudan2009; Bell 2009; Celik 2004), but this may not always be the case for Japanese students in high schools. A large number of studentsmay find making others in their classes laugh a highly appealing element to learning. However, a student who usually finds it hard to speak out in the L2 in front of fellow learners (which can typically be the case in Japanese high schools) may see the added pressure of making their contributions humorous just too much for them to want to do it. Passivity in learning is quite the norm for some students in Japanese high schools and so asking students to take the centre stage as a 'comic' may not only be challenging, but perhaps not the right approach for some students.

In addition, student relationships in the classroomare an important factor in the willingness to communicate. The effect of the 'intergroup climate' (MacIntyre, Clément, Dörnyei and Noels1998: 547) for students during learning on how much a student wishes to speak out or not in the L2 is important to consider, especially if students are asked to add humor to their communication. If a student is not comfortable with the group dynamics they find themselves in (their team and audience), then being humorous will perhaps not be a pleasant experience. Students do not want to tell jokes and get 'heckled' by classmates, and so the group in which students are placed can potentially act as a very strong barrier to using humor.

Another important factor which can act as a powerful influence on humor usageis the attitude the teacher takes towards humor during classes. While some teachers have reported it as an effective way to reduce tension and increase student interest in a class for example (Neuliep 1991), other teachers have associatedtoo much humor with classroom noise and discipline problems (Downs, Javidi and Nussbaum1988). With such beliefs, the production of humorous materials by teachers or students during a class (linked closely to university entrance exams in a Japanese high school for example) may not be looked upon favourably by teachers. Constant laughing amongst students may also give the impression of a lack of seriousness towards the subjectand it is in the hands of the teacher as to how to react to such laughter. Teachers with little knowledge or experience of the potential benefits to learning of the inclusion of humor in materials and communication may discard it as simply 'foolishness' and their resultant attitude towards humor act as a barrier to its use for aiding learning. 
Additionally, too much humor was criticized by someas having serious counter-productive influences on learning (Quock 2007; Ziyaeemehr, Kumar and Abdullah 2011). By acting humorously, using nothing but funny visuals and worksheets, and asking students to be constantly humorous themselves a teacher runs the risk of creating an atmosphere of 'playfulness' and a lack of seriousness' (Ziyaeemehr, Kumar and Abdullah 2011: 115). Askildson (2005: 48) described successful use of humor as finding the balance between 'tension' and 'relaxation' in the class. Too much tension may lead to a lack of motivation for students to participate for example, but an overly relaxed, humorous environment may lead to a loss of classroom control. In fact, using humor may lead to confusion among students if they are disciplined or given bad grades by a teacher after being encouraged to use humor initially (Quock, 2007). In short, teachers need to encourage appropriate 'doses' of humor in instruction to produce any potential learning benefits, whilst closely monitoring and dealing with any noise or discipline issues which may arise as a result of laughter.

A final proposed potential barrierto humor usage for aiding classroom learning is student difficulty in using the L2 to create or understand humor. Visual communication (such as drawings or photos) can bypass such challenges, but asking students to create humorous spoken or written dialogue will increase the complexity of learning. What students will need in this case is sufficient knowledge, support and feedback on how to use English correctly to do so, otherwise humor may be viewed as too difficult to use by many learners.Students using humor in the L2 may need help with not only vocabularyor grammar for example, but also with knowledge about the culture of the L2's nation(s). What is needed is a combination of what Bell called 'linguistic, social and cultural competence' (2007: 28). In terms of what is relevant for Japanese high school classes, this can refer to the actual English language ability of students, their understanding of socially appropriate usage of English humor (if it is not universal humor perhaps), and enough knowledge of the L2's culture to execute culture-specific humor (if desired by the students). A teacher encouraging the use of humor by students should thus be on hand to offer such assistance to students.

\section{Methodology}

\subsection{Study Questions}

The two questions addressed in the study were:

1) What are the overall perceived benefits to learning of teacher and student classroom humor by high school students in Japan?

2) What potential barriers to the use of humor in class by students exist?

\subsection{Participants}

104 students from six different classes in a private Japanese high school participated in the study. Their ages ranged from 15 to 16 and they undertook a communication-based English language class for 50 minutes once a week. Classes were mixed sex classes and consisted of around 20 students each.

\subsection{Data Collection}

Data was collected from students via two surveys (written in the L1) and a set of short open-ended interviews (also conducted in the L1). The first survey (see Section 8.1) targeted student feelings about the benefits of the use of humor in general in school and how often they believed the different sources (the teacher's actions and dialogue, the teacher's materials and visuals, the students' actions and dialogue, and the students' materials) should include humorif the class is considered very important (hence, they should be motivated to learn the content well). The teacher took time to explain the intended meaning of humor(to make people laugh, because something is found to be amusing) before the surveys were completed.

A second survey (see Section 8.2) looked more closely at the specific perceived benefits of the four separate sources of humor discussed above. Students answered questions related to the effect of humor-use on anxiety, retention, participation, enjoyment and classroom atmosphere for each of the four sources by considering their feelings when humor was or was not present. Significant time was taken to explain to students what was meant by the presence of humor in the survey questions, as to avoid any confusion.

A set of interviews (approximately 5-10 minutes long each) conducted with two students after each of the six classes tested were used to shed some more light on possible reasoning for preferences in sources of classroom humor (see Section 8). Any reasons for preferences of use (or non-use) of humor by the teacher or intervieweewere expanded upon in open-ended questioning. 


\section{Results}

\subsection{Question 1 - Student-Perceived Benefits of Humor Usage by Teachers and Students}

The first approach to investigation the potential effects of humor usage on learning was to examine student opinions of the general benefits of humor usage in class (See appendix 8.1). From looking at Table 1 it can be seen that the use of humor in the classroom was on the whole perceived as being beneficial by the students. Survey answers revealed that over 60 per cent of students stated it was mostly or very true that the general use of classroom humor can create relaxation, higher retention, higher participation, more enjoyment and a more comfortable atmosphere. Of most significance was the reported ability of humor to induce relaxation ( $83.7 \%$ of answers 'mostly true' or 'true'), participation ( $78.9 \%$ of answers 'mostly true' or 'true') and enjoyment ( $82.7 \%$ of answers 'mostly true' or 'true'). Also of noticeable interest was that no more than 3 per cent of students believed that any of the suggested benefits of humor on learning were 'not true'.

Table 1. Student opinions of benefits of classroom humor on learning

\begin{tabular}{llllll}
\hline & Relaxation & Retention & Participation & Enjoyment & Atmosphere \\
\hline not true & $1.0 \%$ & $2.9 \%$ & $1.9 \%$ & $0.0 \%$ & $1.9 \%$ \\
slightly true & $6.7 \%$ & $3.8 \%$ & $6.7 \%$ & $3.8 \%$ & $7.7 \%$ \\
moderately true & $8.7 \%$ & $19.2 \%$ & $12.5 \%$ & $13.5 \%$ & $28.8 \%$ \\
mostly true & $33.7 \%$ & $44.2 \%$ & $27.9 \%$ & $17.3 \%$ & $28.8 \%$ \\
very true & $50.0 \%$ & $29.8 \%$ & $51.0 \%$ & $65.4 \%$ & $32.7 \%$ \\
\hline
\end{tabular}

As shown in Table 1, student perceptions of humor usage in the classroom were very positive on the whole.

These findings can be justly criticised as non-revolutionary. It should indeed be expected that a class which has humorous elements arising in it will in fact usually be preferred to a class without much humor. Table 1 serves purely as confirmation that student preferences for humor do in fact also exist in the Japanese high school context. However, by taking the approach of splitting humor usage into teacher-created and student-created during classes, differences in student opinions about simply observing or being asked to demonstrate humor in the $\mathrm{L} 2$ were seen.

Teacher-created humor - By looking at the findings of survey 2 (see appendix 8.2) both the actions and dialogue of the teacher, and the teacher materials and visuals were reported to have positive effects on learning in several different areas. Table 2 below shows thatexcept for the retention element of learning in the study, both sources (teacher actions and dialogue, as well as teacher materials and visuals) were perceived to be all-round beneficial to learning by the students.

Humorous teacher actions and dialogue were reported to be most significantly influential on classroom atmosphere, with 93.3 per cent of students saying that the statement that humor improved class atmosphere was mostly or very true. In addition, students generally believed that is was mostly or very true that humor in teacher actions and dialogue improved relaxation (73.1\%), participation (79.8\%) and enjoyment (79.9\%) in learning. The benefits of a teacher integrating humor into their interaction with their classes are apparent and should not be overlooked by teachers when considering whether or not to attempt to make classes laugh with jokes, gestures and general dialogue. By doing so, teachers can certainly improve their chance of winning the attention of students and potentially create a higher level of willingness to communicate amongst students during activities.

Students also felt that it was either mostly or very true that humorous teacher-produced materials and visuals especially influenced their participation ( $92.3 \%$ of answers) and enjoyment ( $94.2 \%$ of answers) in learning. The creation of a more relaxed state and comfortable class atmosphere were also reported to be very true in over 60 per cent of the student answers. Again, students perhaps felt that as recipients of humor in the form of visual input from the teacher, humor can help to improve how much they enjoy doing class work and how much they wish to actually do it. Using humor as an addition to the 'input' for students in instructional design (what students observe) should without doubt be considered by teachers in Japanese high schools, with such reported benefits. 
Table 2. Benefits to students of humor for the different sources

Teacher actions and dialogue

\begin{tabular}{llllll}
\hline & Relaxation & Retention & Participation & Enjoyment & Atmosphere \\
\hline not true & $0.0 \%$ & $1.9 \%$ & $2.9 \%$ & $0.0 \%$ & $0.0 \%$ \\
slightly true & $7.7 \%$ & $19.2 \%$ & $3.8 \%$ & $3.8 \%$ & $0.0 \%$ \\
moderately true & $19.2 \%$ & $28.8 \%$ & $13.5 \%$ & $16.3 \%$ & $6.7 \%$ \\
mostly true & $30.8 \%$ & $22.1 \%$ & $32.7 \%$ & $21.2 \%$ & $30.8 \%$ \\
very true & $42.3 \%$ & $27.9 \%$ & $47.1 \%$ & $58.7 \%$ & $62.5 \%$ \\
\hline
\end{tabular}

Teacher materials and visuals

\begin{tabular}{llllll}
\hline & Relaxation & Retention & Participation & Enjoyment & Atmosphere \\
\hline not true & $1.0 \%$ & $2.9 \%$ & $1.9 \%$ & $0.0 \%$ & $0.0 \%$ \\
slightly true & $12.5 \%$ & $13.5 \%$ & $1.9 \%$ & $1.0 \%$ & $10.6 \%$ \\
moderately true & $25.0 \%$ & $30.8 \%$ & $3.8 \%$ & $4.8 \%$ & $25.0 \%$ \\
mostly true & $24.0 \%$ & $24.0 \%$ & $20.2 \%$ & $37.5 \%$ & $23.1 \%$ \\
very true & $37.5 \%$ & $28.8 \%$ & $72.1 \%$ & $56.7 \%$ & $41.3 \%$ \\
\hline
\end{tabular}

Student actions and dialogue

\begin{tabular}{llllll}
\hline & Relaxation & Retention & Participation & Enjoyment & Atmosphere \\
\hline not true & $15.4 \%$ & $15.4 \%$ & $22.1 \%$ & $9.6 \%$ & $1.9 \%$ \\
slightly true & $24.0 \%$ & $25.0 \%$ & $23.1 \%$ & $26.0 \%$ & $14.4 \%$ \\
moderately true & $35.6 \%$ & $30.8 \%$ & $24.0 \%$ & $38.5 \%$ & $37.5 \%$ \\
mostly true & $17.3 \%$ & $17.3 \%$ & $20.2 \%$ & $9.6 \%$ & $23.1 \%$ \\
very true & $7.7 \%$ & $11.5 \%$ & $10.6 \%$ & $16.3 \%$ & $23.1 \%$ \\
\hline
\end{tabular}

Student materials and visuals

\begin{tabular}{llllll}
\hline & Relaxation & Retention & Participation & Enjoyment & Atmosphere \\
\hline not true & $29.8 \%$ & $7.7 \%$ & $3.8 \%$ & $4.8 \%$ & $0.0 \%$ \\
slightly true & $25.0 \%$ & $12.5 \%$ & $15.4 \%$ & $8.7 \%$ & $9.6 \%$ \\
moderately true & $24.0 \%$ & $34.6 \%$ & $32.7 \%$ & $20.2 \%$ & $26.0 \%$ \\
mostly true & $15.4 \%$ & $26.0 \%$ & $24.0 \%$ & $26.9 \%$ & $26.0 \%$ \\
very true & $5.8 \%$ & $19.2 \%$ & $24.0 \%$ & $39.4 \%$ & $38.5 \%$ \\
\hline
\end{tabular}

As shown in Table 2, student perceptions of teacher humor were very positive and more mixed opinions arose above student humor usage.

Student-created humor - From an 'output' viewpoint in learning (what students produce), the findings revealed more uncertainty in student preferences (compared to what students observe from the teacher). Questions students answered with regards to humor-use in their own actions and dialogue revealed far less preference on the whole for humor to be demanded in their productive (as opposed to receptive) communication. In fact, a significantly low number of students believed it was mostly or very true that humorous actions and dialogues of their own in class made them more relaxed (25\%), more willing to participate $(30.8 \%)$ or classes more enjoyable (25.9\%). The most positive feedback on humor-use in student actions and dialogue perhaps stood with an improvement to class atmosphere ( $46.2 \%$ saying 'mostly true' or 'very true'), but this is again not a very conclusive opinion from the survey. Teachers should be aware that some students may well not see significant benefit in being humorous themselves in the classroom and it should be left to the intuition of the teacher as to the possible benefits of humor-use based on the students at hand. Some classes for example may well be comfortable with humor in what they are asked to show or say to others, but the added pressure of producing humor in the classroom might sometimes be better left to the teacher. 
Many students did however report that it was either mostly or very trues that humor use in materials and visuals which they create themselves leads to more enjoyment in learning (66.3\%) and a more comfortable class atmosphere (64.5\%). However, as with humor-usage in student actions and dialogue, effects on relaxation, retention and participation were viewed as more inconclusive. As many as $29.8 \%$ of students actually stated that humor use had no effect on relaxation whilst creating materials. Again, teachers should remain aware that humor requested by the teacher in student 'output' (what students say, do or create) should depend on the students at hand. The added demand of creating something humorous may add to the work load for students, but without any real benefit to learning compared to non-humorous communicative output. Therefore, the teacher's intuition should come into play on a case-by-case basis.

\subsection{Question 2 - Barriers to Using Humor}

An additionalapproach to examining how students felt about humor usage in class was to ask them how often they felt both their teacher and they themselves should be using humor in a class important for their future. Table 3 below demonstrates thatanswer from survey 1 (see appendix 8.1) showed a preference for the actions and dialogue of the teacher to be humorous around half the time (51\% of answers) and the materials and visuals provided by the teacher to also be humorous around half the time ( $48.1 \%$ of answers). Also of interest, none of the students stated that the teacher should never be humorous and only 1.9 per cent felt that their materials and visuals should never be humorous.

With regard to the student side of humor in the class, surveys revealed that there was a preference for humorous student action and dialogue to be slightly less frequent than for the teacher. A large number of students stated that their actions and dialogue should be humorous between sometimes and half the time (68.3\% of answers), as should the materials which they produce in class (65.4\% of answers).

Table 3. Student preferences for frequency of humor from the available sources

\begin{tabular}{lllll}
\hline & TA & TM & SA & SM \\
\hline Never & $0.0 \%$ & $1.9 \%$ & $16.3 \%$ & $14.4 \%$ \\
Sometimes & $10.6 \%$ & $20.2 \%$ & $35.6 \%$ & $37.5 \%$ \\
Half the time & $51.0 \%$ & $48.1 \%$ & $32.7 \%$ & $27.9 \%$ \\
Most of the time & $26.9 \%$ & $18.3 \%$ & $9.6 \%$ & $14.4 \%$ \\
Always & $11.5 \%$ & $11.5 \%$ & $5.8 \%$ & $5.8 \%$ \\
\hline
\end{tabular}

$\mathrm{TA}=$ Teacher actions and dialogue $\quad \mathrm{SA}=$ Student actions and dialogue

$\mathrm{TM}=$ Teacher materials and visuals $\quad \mathrm{SM}=$ Student materials and visuals

As shown in Table 3, students expressed a slight preference for humor in the classroom to come more frequently from the teacher rather than themselves.

It could be concludedfromthe above data that on the wholestudents reported an overall preference to be 'observers' of humor rather than 'producers' of it themselves. However, this clearly depends on the student at hand and this was simply a general observation. Following each experimental class student interviews dug a little deeper into reasons which may have existed for any emerging patterns of preferences for use (or non-use) of humor by the students themselves. Several potential barriers to the use of humor by the students arose during interviews. They are summarised in table 4 and are explained below:

Barrier 1 - Firstly, several students mentioned a lack of confidence inwhether using humorwas appropriate or notat certain times and what they should or should not be joking about. Interviewees made comments such as "my teacher might get mad if I joke around", "if my teacher doesn't joke, I shouldn't", and "we get loud when we joke and the teacher shouts at us". A sense of uncertainty about the use of humor seems to stem from the actions of the teacher at hand and perhaps their reaction to humor usage by students. If students are to feel comfortable with using humor to aid their learning, then a teacher clearly needs to encourage its use and react in a supportive manner when the addition of humor is not detrimental to the learning taking place. 
Table 4. Potential barriers to student humor usage identified during interviews

\begin{tabular}{ll}
\hline Barrier & Description \\
\hline 1 & Teacher disapproval of humor usage \\
2 & Group dynamics issues whilst humor is present \\
3 & A lack of seriousness and indiscipline associated with humor usage \\
4 & L2 difficulties in humor usage \\
\hline
\end{tabular}

As shown in table 4, four main potential barriers were identified from the student interviews in the study. They were teacher disapproval, group dynamics issues, a lack of seriousness and indiscipline connected to humor, and L2 difficulties.

Barrier 2 - A second possible reason for students perhaps not preferring to use humor in class themselves is a lack of confidence to do so in front of their partner, group or class as a whole. Comments made such as "It's embarrassing to try to make others laugh", "I don't think my presentations should be humorous, as I'm not funny" and "my friends will make fun of me"revealed anxiety among some students to perform or create things humorously in class. On the other hand, some students stated "I like making my class mates laugh, as it is fun" and "when I can be funny with my friends, I like the class more". Willingness to be humorous in class seems to depend on the student at hand and the audience they face, and so teacher consideration of inter-class relationships should always be present. Teachers needs to stay aware of any discomfort in humor usage which may be arising due to the other people students are working with and be ready to switch group members for example to help overcome this barrier.

Barrier 3 - The third potential barrier to student humor identified from interviews was a lack of seriousnessassociated with a class with significant humorous elements incorporated into it, potentially resulting in a lack of discipline amongst students. Interviewees made comments such as "funny worksheets are fun to do, but are maybe too playful" and "If I start laughing, my friends laugh too and the class gets too loud". This suggests a presence of resistance to humor usage amongst students, due to beliefs that it may not be appropriate in learning. This feeling may come from the teacher, or other sources such as parents, but this may be unknown to the teacher of course.General comments from interviewees such as these suggested that activities which involved playful elements might be motivational for students, but perhaps would cause hesitation and uncertainty in their appropriateness. Again, this is a barrier which could perhaps be overcome if the teacher were to address the benefits of humor usage with a class and even discuss how being playful for example might aid learning (as the students suggested it does in their own survey answers previously).

Barrier 4 - A final barrier for humor usage identified from interviews was one related to issues with the use of the L2 itself. It is clearly more challenging and complex to create language in the L2 which is expected to create an amused reaction amongst its receivers. Students made comments in the interview section related to their own contributions to a class such as "making my classmates laugh is difficult in English", "I can't be funny in English" and "I want to make others laugh, but I don't know enough words to do it". A need for support and guidance from the teacher to give students the ability to use the L2 confidently and successfully with humor is apparent. Perhaps not only with grammatical or lexical items for example, but also with how to deliver humorous material to others as a more confident presenter.

\section{Discussion}

From the findings in this study the use of humor by both teachers and students in the Japanese high school classroom can be fairly viewed as two separate sources in need of different treatment during the design period of a syllabus. Previous research on potential benefits to learning from teacher-created humor were reconfirmed in this study's findings, making it clear to teachers in the Japanese high school context that their own use of humor is potentially useful to enhance learning. Consider a teacher who adds jokes to class, creates worksheets with funny stories included in them, and always attempts to look for a chance to make students laugh in class. It is clear that such a teacher will most likely have more motivated, participating, and enjoyable classes, and should continue to use humor in just such a positive way for learning. However, the same cannot be said for students' contributions to a class. The findings showed much more variation in student opinions on the benefits of them using humor themselves and this is where the teacher's intuition must come into play. Simply put, a teacher must remain aware that making students laugh is perhaps a given motivator, but making students be humorous is not. Consider a student who has little confidence in using the L2, has personal conflicts with their target audience for 
their humor, and believes (for whatever reason) that humor is not appropriate for them to use. Asking that student to create a humorous play about a day in the life of their teacher for example will most likely not result in the student experiencing low anxiety, a willingness to participate, or enjoyment in their learning. Quite the opposite is in fact likely to occur. That being said, sometimes allowing students to not use humor when they wish is a more ideal approach, rather than forcing it upon unwilling students.

From the experimental phase of this report, four main barriers were identified to the use of humor by students in class (assuming that the use of humor will result in positive effects on their learning). Fortunately, the vast majority of answers given during interviews, as to why students might not want to use humor themselves, related to issues which the teacher may have control over. The teacher's opinion of the appropriateness of humor usage in class, who students need to present their humorous language to, and the language required to be humorous in the L2 were three main issues identified. A teacher can in fact attempt to (in part at least) solve these issues through their own actions and teaching practices. A suggested ten step guide of such actions that need to be taken by a teacher (in order to use humor as a positive influence on classroom learning) is set out below.

Table 5. Ten steps for teachers to use humor effectively in learning

\begin{tabular}{ll}
\hline & Step \\
\hline 1 & $\begin{array}{l}\text { Implement humor into your own dialogue and } \\
\text { actions. }\end{array}$ \\
2 & $\begin{array}{l}\text { Implement humor into your classroom } \\
\text { materials and visuals. }\end{array}$ \\
& $\begin{array}{l}\text { Where possible, ensure students only work with } \\
\text { or present to students whom they are } \\
\text { comfortable using humor with. }\end{array}$
\end{tabular}

4 Encourage student humor, but give students the choice of whether to use humor or not.

Explain potential discipline issues to classes (noise for example) that may occur due to humor usage and express your expectations of students' behavior during class work.

Identify when students are uncomfortable with

6 using humor and offer them alternatives in their learning.

7 Provide students with the language and knowledge necessary to be humorous in the $\mathrm{L} 2$.

Give positive feedback for humor usage by students.

Follow up classes with feedback to ensure that

9 students are still performing adequately in their learning.

Be an active and willing participant with humor yourself. A teacher who is enjoying a class themselves is more likely to spread motivation to their students.

Example

Using jokes, humorous gestures and noises in the interactions with students.

Using pictures and videos which induce laughter in the classroom.

Allowing students to form their own choice of groups once humorous output of the task has been explained.

Allowing groups or individuals a choice between producing output such as a comical news report or a serious one (with no preference in choice from the teacher).

Drawing up of class rules with regards to humor usage prior to undertaking classwork.

Offering a switch of activity content (from a comical play to a more dramatic one for example) for students throughout class time.

Allowing groups a practice period with the teacher and feedback on language use before presenting work to their class.

Allocating a score for humor usage in classwork to further demonstrate acceptance and approval of its use.

Obtaining feedback from classes in the form of test scores, interviews, observations or surveys to ensure that humor is having a positive effect on learning.

Creating your own teacher's version of student classwork during class to further emphasize approval and potential enjoyment of using humor.

As Table 5 shows, there are ten recommended approaches to ensuring that humor can be used as a positive influence on classroom learning, without creating a potential for it to act counter-productively towards the 
language learning environment.

By following the above suggested ten steps, a teacher can give themselves the best chance of achieving success with humor as a catalyst for classroom learning. Abrief explanation of each now follows:

Step 1 - The teacher should use humor in their own dialogue and actions during a class. Incorporating jokes, humorous gestures, reaction noises and questions for students during learning for example should (as has been shown in the findings of this study and others) have perceived positive effects on learning.

Step 2 - The use of humor by the teacher in visuals and materials they show the class should also have a positive effect on learning, as previously shown in the findings of the surveys. When considering video clips, pictures or stories to share with a class for example, the inclusion of suitable humor can have a positive effect on enjoyment, participation and the class atmosphere.

Step 3 - The teacher should consider any positive or negative inter-personal relationships between certain students in the class when setting up groups and pairs for class work. Students who are not comfortable with whom they are working with or presenting their humor too are far less likely to be motivated to use it and face barrier 2 (cf. Table 4). Such students should be made to work in separate groups or pairs where possible.

Step 4 - After encouraging students to use humor during class, the teacher should not insist that every student in a class must use humor in their contributions. Some students will simply not be comfortable using it due to one of many possible reasons, ranging from a lack of confidence to be humorous in front of others, even in the L1 (see barrier 2 in Table 4), to a feeling that it is not always appropriate for students to be humorous in a serious classroom setting (see barrier 3 in Table 4). Giving students the option to do class work which contains as much humor for the student as they feel comfortable with will ensure humor is only used as a positive addition to learning and not as a barrier itself.

Step 5 - The teacher will be aware of the potential for a class to become very excited, noisy, and perhaps undisciplined if given the chance to use humor in their learning. The teacher should discuss with a class the potential for these problems to occur before a humorous activity is undertaken. If the teacher merely encourages humor usage, begins an activity, experiences issues with too much noise from a class for example, and then disciplines the class, the teacher is clearly sending mixed messages to the class. The teacher must ensure prior to learning that their expectations for behaviour during class work (and consequences for not reaching those expectations) are known by the students, so that boundaries and limitations are clear once humorous class work begins.

Step 6 - As step 4 pointed out, not every student should be made to use humor in class if they do not wish to. However, some students may decide to undertake this challenge and later change their mind perhaps for whatever reason that may be. The teacher must stay aware of any students who become uncomfortable with their learning, due to the humorous element in it. Simply asking the students whom the teacher suspects may not want to use humor anymore if they wish to continue using it could be a simple way to determine this. Upon finding out a student no longer wishes to use humor, the teacher should offer an alternative non-humorous piece of learning for that student to continue with.

Step 7 - The teacher should be aware that being humorous in the L2 is often not as simple as in the L1. Being on hand to help students with questions related to grammar, vocabulary, or culture is essential to ensure they have the support needed to create humor in the second language.

Step 8 - The teacher should provide a positive reaction to students using appropriate humor, by awarding scores, prizes, praise, or simply generally approving comments when done so. Students experiencing barriers 1 or 3 (cf. Table 4), feeling their teacher may disapprove of their humor or that it is inappropriate for classroom interactions, will potentially feel more confident to use it if the teacher's feedback is approving.

Step 9 - If the above recommended steps one to eight are followed perfectly students are expected to benefit from humor usage in class with a strong possibility of more participation, enjoyment, retention, lowered anxiety and a more comfortable class atmosphere. However, there is no explicit data in this study to show that this will lead to improved language learning or performance from students. This is assumed of course based on student perceptions of how humor can help them learn. Hence, the teacher should follow up the use of humor with sufficient feedback for themselves (with test scores, further surveys for students, or observational data for example) to ensure that classroom learning is actually producing as expected results from students. Without this feedback, the approach being adopted by the teacher to the learning of the students will need alterations (whether that is due to the method in which humor is being used is not certain, but would need consideration). Alternatively, if humor is incorporated and student performance seems to improve, a case can be made for its 
permanent place in a syllabus.

Step 10 - Lastly, The teacher should enjoy the process of humor usage themselves. Laughing and making others laugh is a great experience in any setting. It can create a warmer, more comfortable environment in which a teacher can act as a role model to students in terms of the mentality which should be taken to learning. Things do not need to always be serious, quiet, or even dull for effective learning to be taking place.

\section{Conclusions}

In this study, benefits and barriers to the use of humorin the classroom (described as something visual or audible which results in laughter because it is amusing) were discussed.Areas of particular interest were the tendencyfor humor to be perceived as resulting inlowered anxiety, improved retention, improved participation, increased enjoyment in learning, and a more comfortable classroom atmosphere. Possible barriers preventing the use of humor were identified as teacher disapproval of its use, inter-class student relationship issues creating discomfort for students to use it, and student difficulties using the L2 to be humorous.

Two surveys and a set of short interviews were used in this study to ask high school students questions about the specific benefits of humorin learning. Additionally, questions were asked about how frequently different classroom sources should use humor (in a lesson viewed as important by the students), and the perceived benefits to learning of these separate sources when humorous.

On the whole, findings revealed that students felt (as expected) that humor was very beneficial to learning and can lower anxiety, improve retention, promote higher levels of participation, result in more enjoyment and create a more comfortable class atmosphere.

Afurther breakdown of humor into teacher-created and student-created revealed that humor emanating from the teacher's actions, dialogue, materials and visuals were seen to have very significantly positive effects on classroom learning. Additionally, humorous student actions, dialogue, materials and visuals were perceived by the participants to result in positive influences on learning.

However, there was generally less commitment from the students in the surveys to state that their own humorous contributions should be frequent during class or that they would result in lowered anxiety, a higher willingness to participate, or improved retention compared to the effect of the teacher using humor. This hesitation to state that using humor makes classes more memorable, attractive to take part in, or relaxing suggesteda possible presence of some discomfort amongst students in using humor themselves.

Four possible barriers were identified for students using humor as a beneficial addition in their learning from student interviews (although interviews were small in numbers and not of a great enough length to draw concrete conclusions from). They were teacher disapproval of humor, group dynamic issues for students, a lack of seriousness and discipline associated with humor and difficulties using the L2 to be humorous. Using the findings of this report a ten-step guideline of recommended actions was produced for teachers to follow to usehumor in a classroom to enhance learningwith little or no negative resultant effects on learning expected (see Section 5).

To summarize, the use of humorin learning is perceived to have great benefits amongst students in Japanese high schools, but faces some challenging barriers to its successful implementation. Some of these barriers are linked to deep-rooted personality traits for example (such as a belief that humor is never appropriate in learning), and others to situation-specific factors such as direct teacher feedback. If humor is to find its place in the language classroom the teacher must focus upon what they have the ability to alter in the learning environment and upon their own classroom behaviour. A teacher should attempt to integratehumor into what they say, do and show classrooms and simultaneously cautiously require their students to be humorous in what they say, do and present (whilst being aware of barriers which may be present and prevent its acceptance in class by students). By following the ten-step guideline set out in this report it is likely that humor can be used as a useful and manageable addition to the EFL classroom.

\section{References}

Aboudan, R. (2009). Laugh and learn: Humor and learning a second language. International Journal of Arts and Sciences, 3(3), 90-99.

Askildson, L. (2005). Effects of humor in the language classroom: Humor as a pedagogical tool in theory and practice. Arizona Working Papers in SLAT, 12, 45-61.

Bell, N. (2005). Exploring L2 language play as an aid to SLL: A case study of humour in NS-NNS interactions. Applied Linguistics, 26(2), 192-218. http://dx.doi.org/10.1093/applin/amh043 
Bell, N. (2007). How native and non-native English speakers adapt to humor in intercultural communication. Humor, 20(1), 27-48. http://dx.doi.org/10.1515/HUMOR.2007.002

Bell, N. (2009). Learning about and through humor in the second language classroom. Language Teaching Research, 13(3), 241-258. http://dx.doi.org/10.1177/1362168809104697

Celik, M. (2004). Humor: What can it do for tertiary students? Hacettepe University Journal of Education, 27, 59-66.

Chee, A. (2006). Humor in TEYL-Reducing classroom anxiety. The international TEYL journal. Retrieved August 10, 2012, from http://www.teyl.org/article2.html

Downs, V., Javidi, M., \& Nussbaum, J. (1988). An analysis of teachers' verbal communication within the college classroom: Use of humor, self-disclosure, and narratives. Communication Education, 37, 127-141. http://dx.doi.org/10.1080/03634528809378710

Ghaffari, M. (2012). The effect of context (humorous vs. Non-humorous) on vocabulary acquisition and retention of Iranian EFL learners. International Journal of Applied Linguistics and English Literature, 1(6), 222-231. http://dx.doi.org/10.7575/ijalel.v.1n.6p.222

Golchi, M., \& Jamali, F. (2011). The effect of teacher's verbal humor on advanced learner's classroom anxiety. European Journal of Social Sciences, 26(2), 185-192.

Gorham, J., \& Christophel, D. M. (1990). The relationship of teachers' use of humor in the classroom to immediacy and student learning. Communication Education, 39, 46-62. http://dx.doi.org/10.1080/03634529009378786

Hayati, A., Shooshtari, Z., \& Shakeri, N. (2011). Using humorous texts in improving reading comprehension of EFL learners. Theory and Practice in Language Studies, 1(6), 652-661. http://dx.doi.org/10.4304/tpls.1.6.652-661

MacIntyre, P., Clément, R., Dörnyei, Z., \& Noels, K. (1998). Conceptualizing willingness to communicate in a L2: A situated model of confidence and affiliation. Modern Language Journal, 82(4), 545-562. http://dx.doi.org/10.1111/j.1540-4781.1998.tb05543.x

Minchew, S., \& Hopper, P. (2008). Techniques for using humor and fun in the language arts classroom. Clearing House, 81(5), 232-236. http://dx.doi.org/10.3200/TCHS.81.5.232-236

Neuliep, J. (1991). An examination of the content of high school teacher's humor in the classroom and the development of an inductively derived taxonomy of classroom humor. Communication Education, 40, 343-355. http://dx.doi.org/10.1080/03634529109378859

Oda, S. (2006). Laughter and the traditional Japanese smile. In J. Davis (Ed.), Understanding humor in Japan (pp. 15-26). Detroit: Wayne State University Press.

Quock, T. H. (2007). The role of humor in the EFL classroom. Keisen University Bulletin, 19, 165-176.

Rafiee, M., Kassaian, Z., \& Dastjerdi, H. (2010). The application of humorous songs in EFL classrooms and its effects on listening comprehension. English Language Teaching, 3(4), 100-108.

Raskin, V., \& Attardo, S. (1994). Non-literalness and non-bona-fide in language: An approach to formal and computational treatments of humor. Pragmatics \& Cognition, 2(1), 31-69. http://dx.doi.org/10.1075/pc.2.1.02ras

Schmitz, J. R. (2002). Humor as a pedagogical tool in foreign language and translation courses. Humor, 15(1), 89-113. http://dx.doi.org/10.1515/humr.2002.007

Shade, A. (1996). License to laugh: Humor in the classroom. Connecticut: Greenwood publishing.

Tamaoka, K., \& Takahashi, T. (1994). Understanding humor from another culture: Comprehension of parental brain twisters by Japanese university students learning English as a second language. Psychologia, 37, 150-157.

Torok, S. E., McMorris, R. F., \& Lin, W. C. (2004). Is humor an appreciated teaching tool? Perceptions of professors' teaching styles and use of humor. College Teaching, 52(1), 14-20. http://dx.doi.org/10.3200/CTCH.52.1.14-20

Zhao, Y., \& Fan, S. (2010). Bringing humor into ESL classrooms: Asian students' perspectives. Global Studies Journal, 3(2), 105-116. 
Ziyaeemehr, A., Kumar, V., \& Abdullah, M. (2011). Use and non-use of humor in academic ESL classrooms. English Language Teaching, 4(3), 111-119. http://dx.doi.org/10.5539/elt.v4n3p111

\section{Appendices}

Appendix 1 - Survey 1

(answer either 'not true', 'slightly true',' moderately true', 'mostly true', or 'very true')

1. When a subject makes me laugh a lot I want to take part more

2. Classesin which I laugh a lot are more fun to do

3. Laughing during class time makes me feel more relaxed about learning

4. Subjects in which I laugh a lot don't help me learn any easier (reversed)

5. There is a more comfortable class environment when everyone is laughing more

How often do you think each of the following should be humorous in a class which is very important for your future?

(Answer either 'never', 'sometimes', 'half the time', 'most of the time', or 'always')

1. What the teacher says or does

2. The material our teacher shows or gives us

3. The things you have to act out or say

4. The things you have to write or draw

Appendix 2 - Survey 2

Part 1 - about your teacher

(Answer either 'not true', 'slightly true',' moderately true', 'mostly true', or 'very true')

1. Humorous worksheets are more fun to look at than other sheets

2. A humorous teacher makes our class atmosphere more relaxed

3. A humorous teacher doesn't make me want to take part more (reversed)

4. I enjoy learning more with a humorous teacher

5. I can remember English easier when my teacher is being humorous

6. My class atmosphere is much better when we use humorous materials

7. Humorous worksheets are just as boring to read as non-humorous ones (reversed)

8. I can remember English more easily if worksheets are humorous

9. I feel more relaxed in the class when my teacher makes me laugh

10. Humorous materials in class makes me feel more relaxed about learning

Part 2 - about yourself

(Answer either 'not true', 'slightly true',' moderately true', 'mostly true', or 'very true')

1. I enjoy saying/acting humorous things in class

2. I want to work harder when the materials I have to produce are humorous compared to not humorous

3. I feel anxious when I have to do/say something humorous compared to something non-humorous in my class (reversed)

4. I can remember English easier when I have to say/act out something humorous

5. I feel nervous when I need to make something humorous in my class (reversed)

6. I feel like working harder when what I have to say/act is humorous

7. Our class atmosphere is more comfortable when we are making humorous materials

8. It is more fun for me to make non-humorous materials than humorous ones (reversed)

9. Our class atmosphere is more relaxed when we have to be humorous in front of each other

10. I remember what I have learnt better when I make something humorous as opposed to not humorous 


\section{Appendix 3 - Interview questions}

How often should the following be humorous in the class? Why do you think so?

- Your teacher's dialogue/actions

- Your teacher's materials/visuals

- Your own dialogue/actions

- You own materials/visuals

\section{Copyrights}

Copyright for this article is retained by the author(s), with first publication rights granted to the journal.

This is an open-access article distributed under the terms and conditions of the Creative Commons Attribution license (http://creativecommons.org/licenses/by/3.0/). 